\title{
Sistem Informasi Pemesanan Tiket Konser Musik Theater Berbasis Website
}

\author{
Khuzaipi ${ }^{1}$, Melan Susanti ${ }^{2}$, Mari Rahmawati ${ }^{3}$ \\ Universitas Nusa Mandiri ${ }^{1,2}$, Universitas Bina Sarana Informatika ${ }^{3}$ \\ 11190522@nusamandiri.ac.id¹, melan.msu@nusamandiri.ac.id², mari.mrw@bsi.ac.id ${ }^{3}$
}

\begin{abstract}
Abstrak - Dalam era globalisasi sekarang ini, teknologi informasi melaju dengan cepatnya. Adapun komputer yang merupakan peralatan yang diciptakan untuk mempermudah pekerjaan manusia, saat mencapai kemajuan baik di dalam pembuatan hardware maupun software. Media web dapat menjadi sarana promosi, bisnis, komunikasi bahkan menjadi sumber berita dan informasi. Melalui media web para pengunjung dapat mencari informasi yang dibutuhkan serta menambah wawasan dan pengetahuan dari berbagai bidang ilmu. Pengunjung juga dapat melihat informasi konser yang akan dilaksanakan dan juga berisi informasi tentang artis yang akan konser, penelitian ini membahas tentang pemesanan tiket konser musik teater, pembuatan program web ini menggunakan Adobe Dreamweaver CS5, Apache, PHP, dan Xampp. Website ini berfungsi untuk memberikan informasi tentang konser-konser yang akan diselenggarakan dan tata cara pemesanan tiket yang tersedia. Tujuan website ini adalah untuk mempermudah users dalam memperoleh informasi terbaru mengenai konser-konser yang akan diselengarakan di indonesia serta users dapat memesan tiket secara mudah dan cepat, hal ini sangat membantu para penggemar fans musik diseluruh tanah air bila ingin menonton konser musik kesayangan mereka secara langsung. Dan juga dengan web ini dapat mengetahui informasi mengenai konser-konser musik yang ada dan tanggal berapa serta wilayah mana akan diselenggarakan, sekaligus juga dapat mengetahui harga tiket yang sudah disediakan.
\end{abstract}

Kata Kunci: Sistem Informasi, Tiket musik, Web

\begin{abstract}
Right now in this era of globalization, the information technology accelerates so fast. Meanwhile with the presence of computer which is one of many sophisticated instruments made by people is really helpful and to ease people's work due to the emerging of both the hardware and software. Web media can be a means of promotion, business, communication and even become a source of news and information. Through web media, visitors can search for information needed and add insight and knowledge from various fields of science. Visitors can also see the concert information to be performed and also contains information about the artist to be concert, this research is about booking teater music concert tickets, making this web program using Adobe Dreamweaver CS5, Apache, PHP, and Xampp. This website serves to provide information about the concerts to be held and the procedure of booking tickets are available. The purpose of this website is to facilitate users in obtaining the latest information about concerts that will be held in Indonesia and users can order tickets easily and quickly, it is very helpful to fans music all over the country if you want to watch their favorite music concert directly. And also with this web can find information about the music concerts that exist and the date of how and which region will be held, as well as to know the price of tickets that have been provided.
\end{abstract}

Keywords: Information System, Ticket Music, Web

\section{PENDAHULUAN}

Website merupakan kumpulan halaman yang dipakai untuk memperlihatkan informasi teks, gambar tidak bergerak atau gerak, animasi, suara, dan gabungan dari semuanya, baik yang bersifat dinamis maupun statis yang membentuk satu rangkaian bangunan yang saling bersangkutan, masing-masing dihubungkan oleh rangkaian halaman(Astika, 2019). Sekarang internet telah menjadi keperluan dan gaya hidup masyarakat. Bidangbidang yang mendapat pengaruh diantaranya pemasaran, promosi, penjualan dan sebutlah bisnis secara elektronik(Kartini \& Popong, 2018).

Tetapi perkembangan komputer yang begitu cepat juga harus didukung oleh sumber daya manusia yang handal dan siap pakai agar dapat lebih cepat menyesuaikan diri, kerja dengan baik dan benar sehingga dapat memanfaatkan sepenuhnya teknologi komputer untuk mencapai tujuan yang telah direncanakan. dalam proses perniagaan yaitu dalam memesan tiket yang menggunakan sistem manual dengan menggunakan tiket kertas membutuhkan antrian yang panjang dan cara memasarkannya masih manual sehingga untuk mengetahui jadwal konser musik masih sangat kurang dalam memberikan informasi serta penyampaian kepada pembelinya (Saryoko, 2017). Maka hal ini kurang efektif bagi pengguna yang hanya ingin mencari informasi seputar konser saja(Pinandita et al., 2019).

Melihat dalam pemesanan tiket konser musik banyak yang masih manual belum komputerisasi sehingga pelayan pemesanan 
tiket tersebut terasa lebih lama dan kurang terprogram dengan baik, dapat mengakibatkan kesalahan, maka hal ini dapat menciptakan efektifitas dan efisiensi dalam hal pemasaran dan pelayanan perusahaan. Oleh karena itu penulisan merancang program berbasis komputer disamping bisa meningkatkan pelayanan kepada calon pembeli tiket konser musik, juga akan mempermudah pihak manajemen dalam melakukan pemeliharaan data dan dapat memperoleh laporan yang lebih cepat dan akurat(Haryanti \& Fachrurozi, 2017).

\section{METODOLOGI PENELITIAN}

Sistem Teknik pengumpulan data yang digunakan oleh penulis dalam melakukan pengumulan data adalah :

A. Observasi (observation)

Dalam metode ini penulis mengumpulkan data dengan cara pengamatan langsung maupun melihat situs-situs pemesanan tiket lainnya yang sudah ada. Untuk mengetahui kebutuhan dan keinginan para costumer, agar dapat dipercaya dan menjadi lebih efisien dalam pemesanan tiket musik secara online.

B. Studi Pustaka (library research)

Dalam metode ini penulis mengumpulkan dan memperoleh data dari membaca buku, laporan-laporan, jurnal, e-book, website atau bacaan lainnya, berkaitan dengan bahan atau materi yang akan dibahas.

Metode yang digunakan pada pengembangan perangkat lunak ini menggunakan System Development Life Cycle (SDLC) yang meliputi :

1. Analisa Kebutuhan Perangkat Lunak Pada proses ini penulis lebih mengutamakan mengenai proses pemesanan tiket secara online. Hal ini dilakukan untuk mempermudah proses transaksi penjualan dan memberikan kemudahan tersendiri kepada pengguna internet yang akan memesan atau memperoleh informasi pada website pemesanan tiket konser musik.

2. Desain

Pada proses ini merupakan tahapan dimana dilakukan penuangan pemikiran dan perancangan sistem terhadap solusi dari permasalahan yang ada dengan menggunakan perangkat permodelan sistem seperti diagram hubungan entitas (entity relationship diagram), hubungan antara tipe record (logical record structure), tools system mengunakan Unified Modeling Language (UML), serta struktur dan bahasan data.

3. Pembuatan Kode Program

Pembuatan kode program atau coding merupakan penerjemahan design dalam bahasa yang dikenal oleh komputer. Dilakukan oleh programmer yang akan menerjemahkan transaksi yang diminta user. Tahap ini adalah tahap sebenar dalam mengerjakan sistem dalam arti pengguna komputer akan dimaksimalkan pada tahap ini. Setelah pengkodean selesai, pengujian akan dilakukan pada sistem yang dibuat sebelumnya. Tujuan testing adalah menentukan kesalahan-kesalahan terhadap sistem tersebut dan kemudian bisa diperbaiki.

4. Impementasi dan Pengujian Unit Pada proses ini perancangan perangkat lunak direalisasikan sebagai serangkaian program atau unit program, desain interface perangkat lunak pada website pemesanan tiket online direalisasikan sebagai serangkain program atau sebuah unit program. Dilakukan juga unit pengujian program website pemesanan tiket online yang melibatkan verifikasi sistem, bahwa setiap unit sudah memenuhi spesifikasinya.

5. Penerapan Program dan Pemeliharaan Perangkat lunak yang sudah dibuat dan diterapkan pada perangkat lunak lain akan mengalami perubahan. Perubahan ini dapat terjadi secara tidak sengaja, karena perangkat lunak harus menyesuaikan diri dengan lingkungan (periperal atau sistem baru) atau karena pengguna memerlukan pengembangan fungsional.

\section{HASIL DAN PEMBAHASAN}

Suatu sistem yang terdiri dari berbagai kumpulan prosedur yang saling terkait satu dengan yang lain yang bertujuan untuk menyelesaikan suatu masalah disebut dengan proses bisnis. Sistem berjalan pada pemesanan tiket konser musik khususnya pada sistem pemesanan ini masih bersifat manual dengan prosedur.

1. Pemesanan Tiket

Customer datang langsung ke tempat konser lalu dapat melihat poster artis yang ingin ditonton kemudian mengisi form pemesanan tiket,

2. Pembayaran Tiket

Customer menuju loket yang sesuai dengan artis yang ingin ditonton. kemudian admin memberikan tiket sesuai permintaan customer dan customer membayar langsung tiket dan dapat memilih kursi yang akan ditempati dengan cara melihat denah kursi pada kertas denah kursi. Customer dapat masuk studio sesuai jadwal yang ditentukan, dengan menunjukkan tiket kepada petugas

3. Pembuatan laporan penjualan

Admin memberikan laporan penjualan perhari dengan merekap data penjualan tiket kepada manager. Lalu manager memberikan laporan tersebut kepada agen artis setiap bulannya. 


\section{A. Activity Diagram Sistem Informasi Tiket} Activity Diagram adalah diagram yang menggambarkan worlflow (aliran kerja) atau aktivitas dari sebuah sistem atau proses bisnis. Yang perlu diperhatikan adalah bahwa diagram aktivitas menggambarkan aktivitas sistem bukan apa yang dilakukan aktor, jadi aktivitas yang dapat dilakukan oleh sistem.

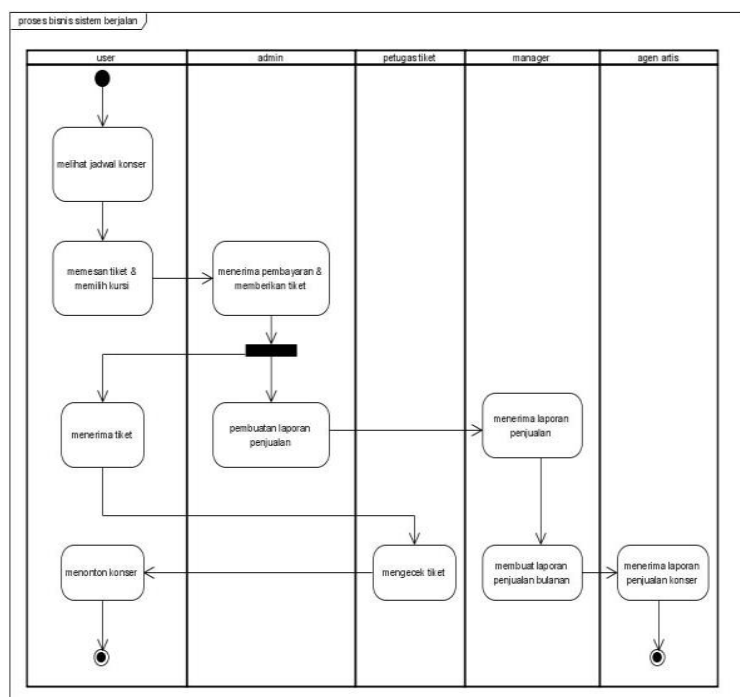

Sumber: (Khuzaipi et al., 2020)

Gambar 1. Activity Diagram Sistem Informasi Tiket

\section{B. Analisis Kebutuhan Software}

Proses analisa kebutuhan yang dilakukan penulis bertujuan agar pengunjung website memahami dan mengenal pemesanan tiket konser musik onile berbasis website yang telah dibuat. Pada dasarnya sistem pemesanan di website ini mengutamakan kenyamanan dalam melakukan pemesanan tiket tanpa harus antre di loket atau kantor agen.

\section{Halaman User}

A1. User dapat mendaftar menjadi member

A2. User dapat login dengan account yang telah dibuat

A3. User dapat memilih data konser meliputi kategori artis dan studio

A4. User melakukan Checkout

A5. User bisa melakukan konfirmasi pembayaran

\section{Halaman Admin}

B1. Admin dapat melakukan login pada account yang telah dibuat

B2. Admin dapat mengelola data artis

B3. Admin dapat mengelolah data transaksi

B4. Admin dapat mengelolah data account

\section{Use Case Diagram}

Usecase diagram adalah diagram usecase yang digunakan untuk menggambarkan secara ringkas siapa yang menggunakan sistem dan apa saja yang bisa dilakukannya. Diagram usecase tidak menjelaskan secara detail tentang penggunaan usecase, namun hanya memberi gambaran singkat hubungan antara usecase, aktor, dan sistem.

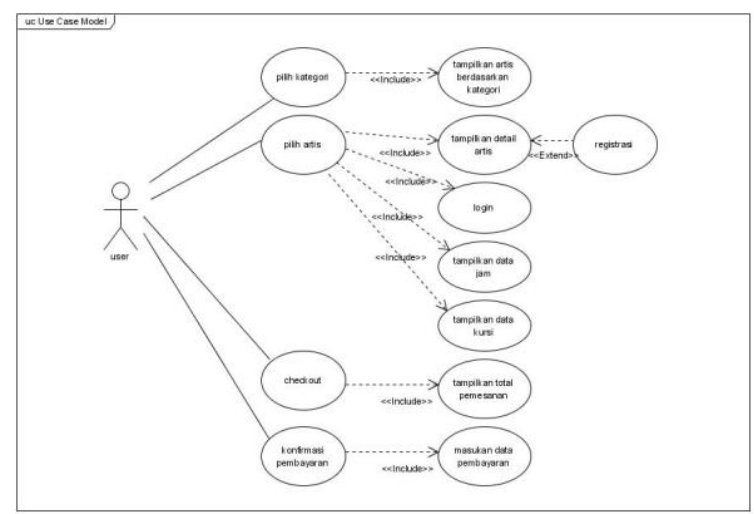

Sumber: (Khuzaipi et al., 2020)

Gambar 2. Use Case Diagram Halaman User

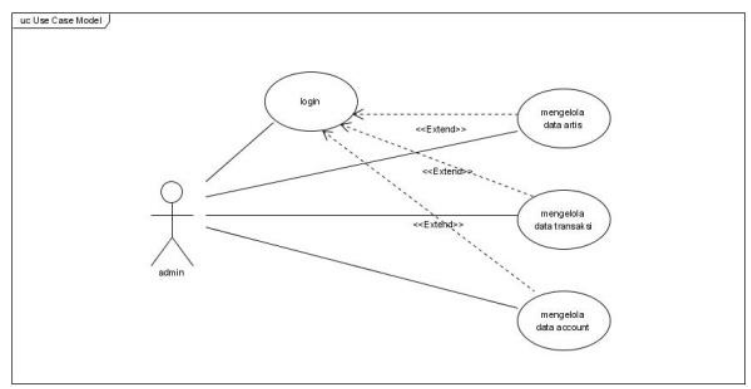

Sumber: (Khuzaipi et al., 2020)

Gambar 3. Use Case Diagram Halaman Admin

\section{Activity Diagram}

Activity Diagram adalah Diagram yang menggambarkan worlflow (aliran kerja) atau aktivitas dari sebuah sistem atau proses bisnis. Yang perlu diperhatikan adalah bahwa diagram aktivitas menggambarkan aktivitas sistem bukan apa yang dilakukan aktor, jadi aktivitas yang dapat dilakukan oleh sistem. 


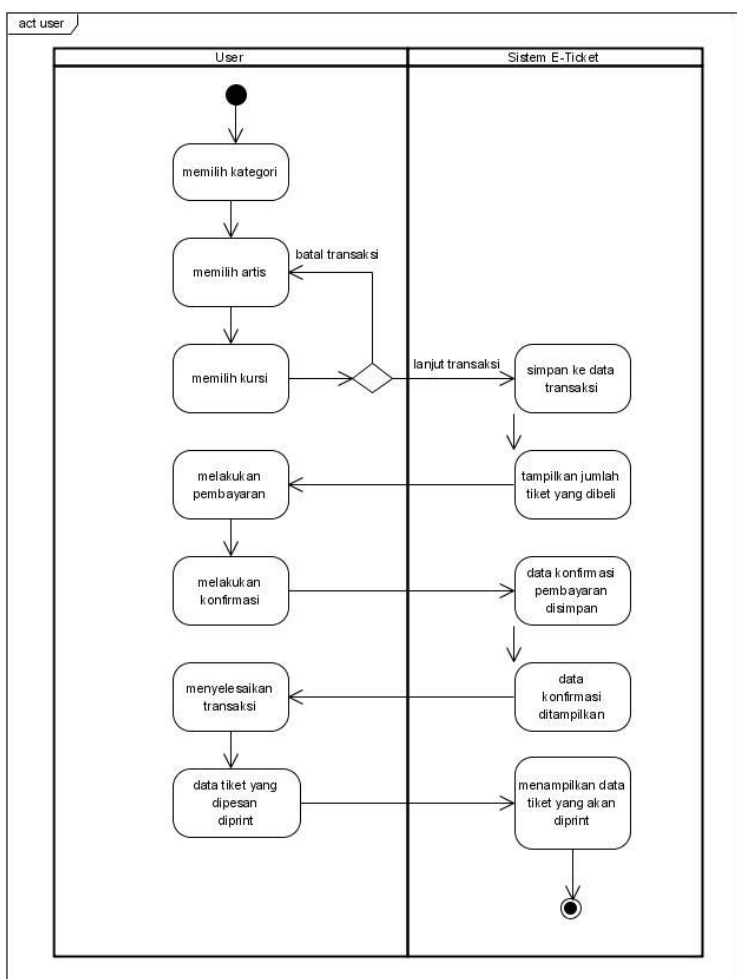

Sumber: (Khuzaipi et al., 2020)

Gambar 4. Activity Diagram Halaman User

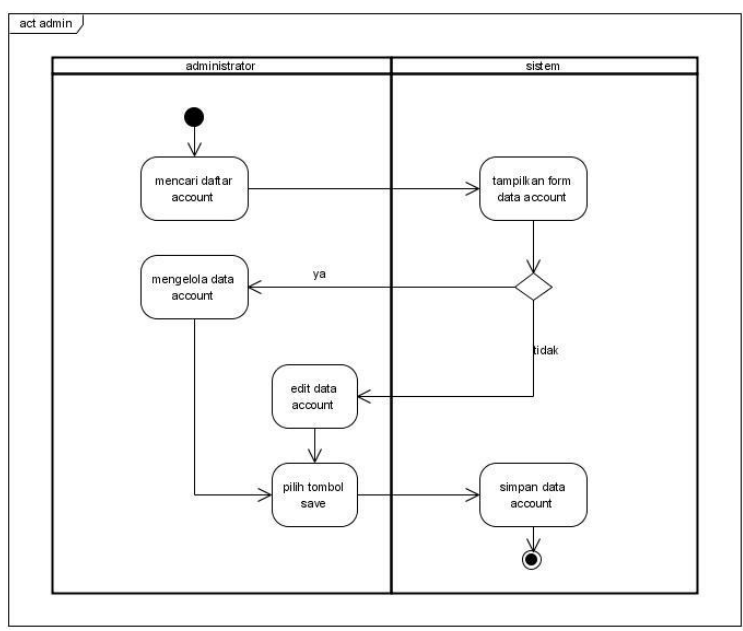

Sumber: (Khuzaipi et al., 2020)

Gambar 5. Activity Diagram Admin Mengelola Data Artis

\section{F. User Interface}

User interface atau rancangan layar merupakan salah satu komponen dari sistem yang dirancang berfungsi sebagai sarana komunikasi antara user dan program sistem yang nantinya akan digunakan.
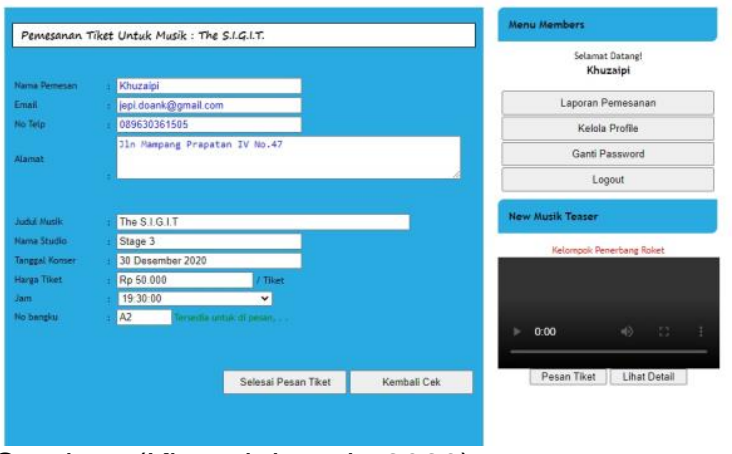

Sumber: (Khuzaipi et al., 2020)

Gambar 6. Form Pemesanan Tiket

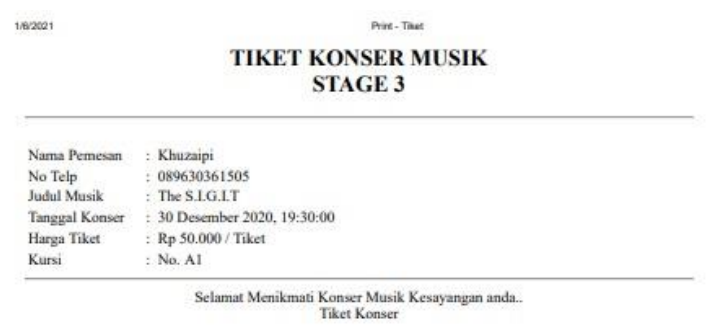

Sumber: (Khuzaipi et al., 2020) Gambar 7. Form Cetak Tiket

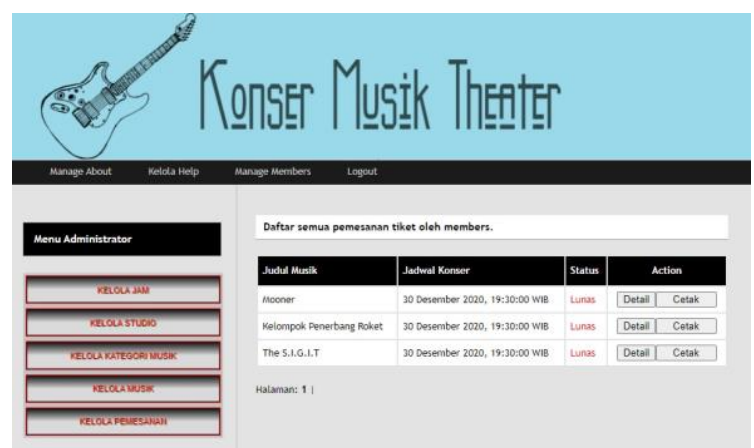

Sumber: (Khuzaipi et al., 2020)

Gambar 8. Form Laporan Pemesanan

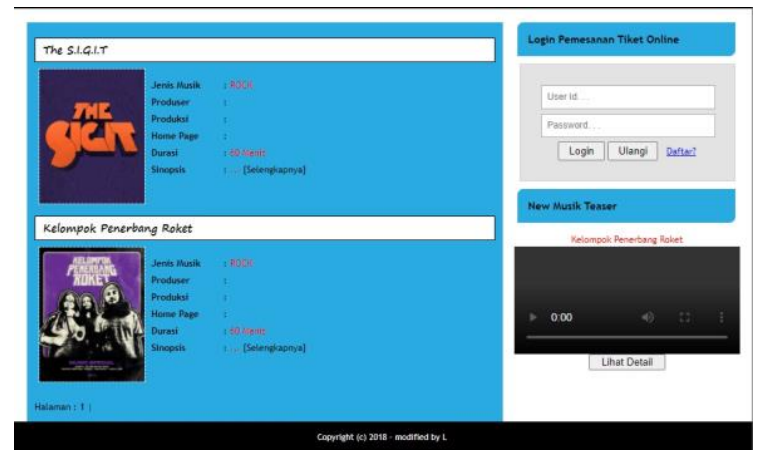

Sumber: (Khuzaipi et al., 2020)

Gambar 9. Beranda User 


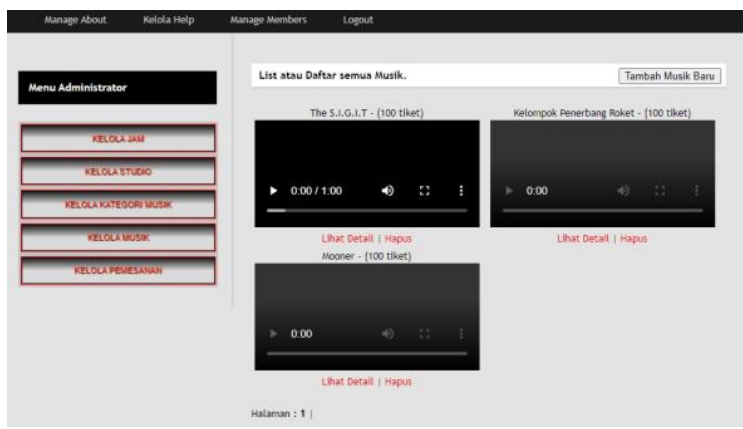

Sumber: (Khuzaipi et al., 2020) Gambar 10. Beranda Admin

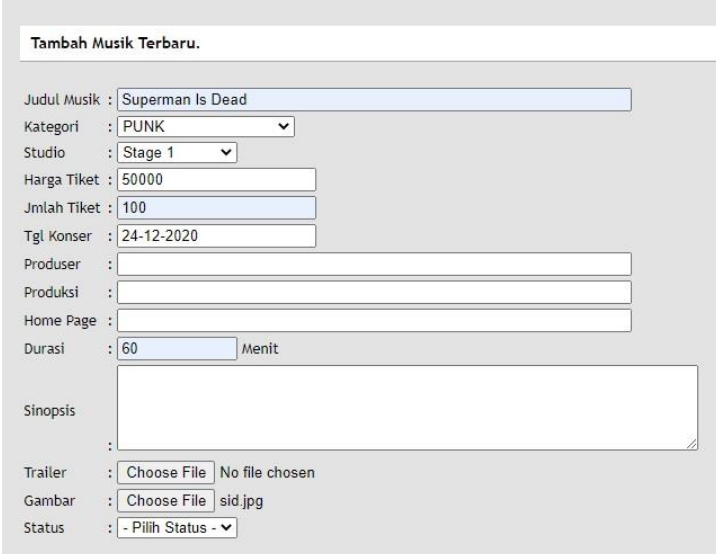

Sumber: (Khuzaipi et al., 2020)

Gambar 11. Form Input Artis

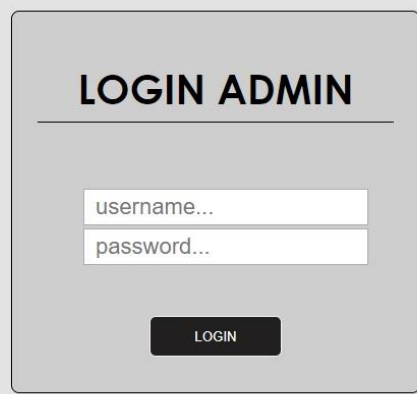

Sumber: (Khuzaipi et al., 2020)

Gambar 12. Form Login Admin

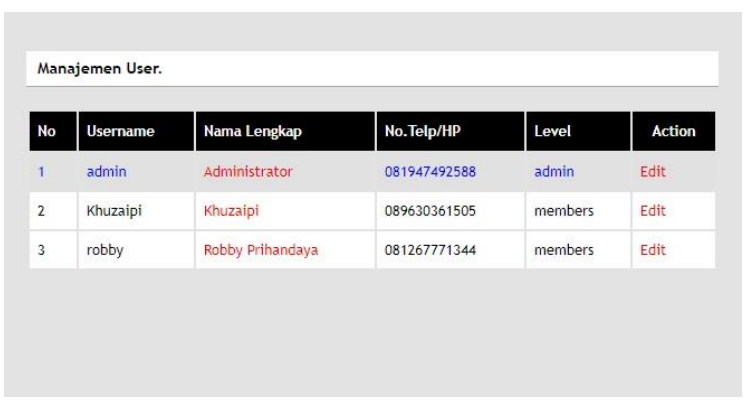

Sumber: (Khuzaipi et al., 2020)

Gambar 13. Form Manage Member

\section{KESIMPULAN}

Dari pembahasan diatas mengenai sistem pemesanan tiket konser music yaitu Penggunaan sistem layanan e-commerce interaktif untuk pembelian tiket konser ini memberikan kemudahan kepada konsumen dalam pemesanan tiket konser melalui web. Karena pembeli dapat melihat berbagai tiket konser yang ditawarkan tanpa harus mengunjungi agen penjualan tiket konser tersebut, user juga dapat melihat data lebih cepat dan dapat mengakses informasi di mana saja, selama terkoneksi dengan internet, kemudian menjadi sebuah terobosan baru penjualan tiket konser musik secara "online", dan akan menjadi program yang lebih mudah dan fleksibel untuk digunakan.

Setelah mengambil kesimpulan yang dilakukan oleh penulis, penulis memberikan beberapa saran, adapun saran-saran yang dapat penulis sampaikan, Penggunaan sistem layanan $e$ commerce interaktif untuk pembelian tiket konser ini memberikan kemudahan kepada konsumen dalam pemesanan tiket konser melalui web. Karena pembeli dapat melihat berbagai tiket konser yang ditawarkan tanpa harus mengunjungi agen penjualan tiket konser tersebut. user dapat melihat data lebih cepat dan dapat mengakses informasi di mana saja, selama terkoneksi dengan internet. bermanfaat dan menjadi sebuah terobosan baru penjualan tiket konser musik secara "online", dan akan menjadi program yang lebih mudah dan fleksibel untuk digunakan.

\section{REFERENSI}

Astika, R. (2019). Sistem informasi pengelolaan tiket dan fasilitas objek wisata di pantai mutun. 3, 126-143

Haryanti, T., \& Fachrurozi, M. M. (2017). Rancang Bangun Sistem Informasi Penjualan Peralatan Parking System Pada Pt. Autoparking Indonesia. None, 13(2), 245-248. https://doi.org/10.33480/pilar.v13i2.687

Kartini, \& Popong, S. (2018). Sistem Reservasi E-ticketing Pesawat Multi-tier $T$ erintegrasi. 8-9. http://digilib.mercubuana.ac.id/manager/t! @file_artikel_abstrak/Isi_Artikel_1840621 57069.pdf

Khuzaipi, Susanti, M., \& Rahmawati, M. (2020). Sistem Infromasi Pemesanan Tiket Konser Musik Theater Berbasis Web.

Pinandita, R., Pradana, F., Hayuhardhika, W., \& Putra, N. (2019). Pengembangan Sistem Informasi Pemesanan Tiket Konser Malang Berbasis Web. 3(7).

Saryoko, A. (2017). Sistem Informasi Tiket Bioskop Pada Buaran Teater Di Jakarta 
Timur Berbasis Web. Jurnal Pilar Nusa Mandiri, 13(1), 98-102.

Abdul Kadir. (2014). Pengenalan Sistem Informasi (Revisi). Andi.

Laudon, K. C., \& Traver, C. G. (2017). ECommerce (13th ed.).

Aditama, R. (2013). Sistem Informasi Akademi Kampus Berbasis Web Dengan PHP. Lokomedia.

Bin Ladjamudin, A.-B. (2013). Analisis dan Desain Sistem Informasi. Graha IImu.

Susianto, D. (2019). Perancangan Sistem Pemesanan E-Tiket Pada Wisata Di
Lampung Berbasis Web Mobil. 2, 60-71. Septian, O. (2019). Analisa perancangan sistem informasi pemesanan tiket museum online di dki jakarta berbasis web. 10(1), 1-5.

Rahmat, A., \& Octaviano, A. (2016). Aplikasi Pemesanan Tiket Bus Berbasis Web (Studi Kasus pada PO. Harapan Jaya). Jurnal Informatika Universitas Pamulang, 1(1), 1-11. 